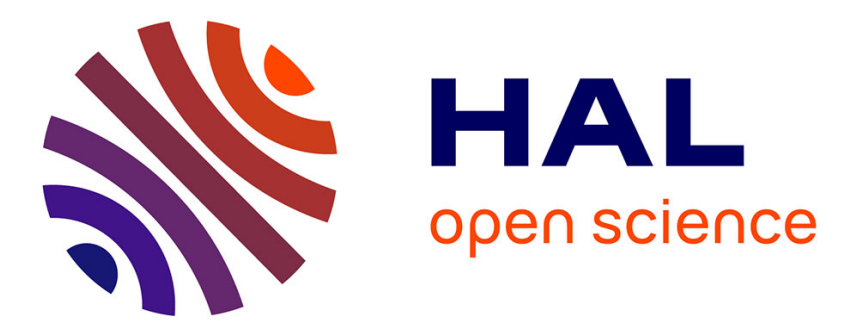

\title{
Management of vapor release in secondary refrigeration processes based on hydrates involving $\mathrm{CO} 2$ as guest molecule
}

\author{
Ziad Youssef, Laurence Fournaison, Anthony Delahaye, Michel Pons
}

\section{- To cite this version:}

Ziad Youssef, Laurence Fournaison, Anthony Delahaye, Michel Pons. Management of vapor release in secondary refrigeration processes based on hydrates involving $\mathrm{CO} 2$ as guest molecule. International Journal of Refrigeration, 2019, 98, pp.202-210. 10.1016/j.ijrefrig.2018.11.017 . hal-01958823v2

\section{HAL Id: hal-01958823 \\ https://hal.science/hal-01958823v2}

Submitted on 13 Dec 2019

HAL is a multi-disciplinary open access archive for the deposit and dissemination of scientific research documents, whether they are published or not. The documents may come from teaching and research institutions in France or abroad, or from public or private research centers.
L'archive ouverte pluridisciplinaire HAL, est destinée au dépôt et à la diffusion de documents scientifiques de niveau recherche, publiés ou non, émanant des établissements d'enseignement et de recherche français ou étrangers, des laboratoires publics ou privés. 


\section{Accepted Manuscript}

Management of vapor release in secondary refrigeration processes based on hydrates involving $\mathrm{CO} 2$ as guest molecule

Ziad Youssef, Laurence Fournaison, Anthony Delahaye, Michel Pons

PII:

DOI:

Reference:

To appear in:

Received date:

Revised date:

Accepted date:
S0140-7007(18)30461-4

https://doi.org/10.1016/j.jirefrig.2018.11.017

JIJR 4177

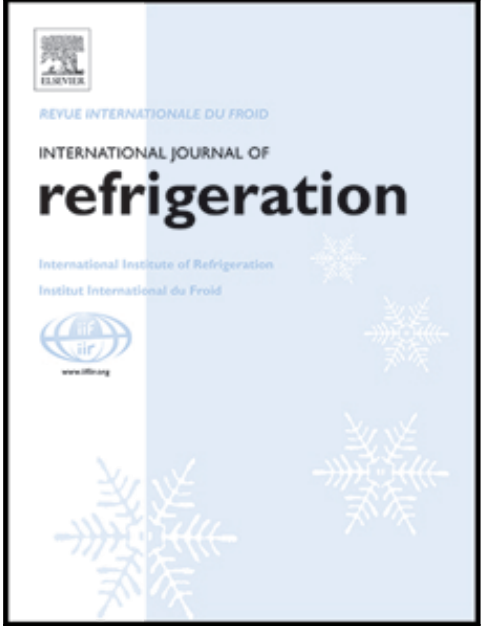

Please cite this article as: Ziad Youssef, Laurence Fournaison, Anthony Delahaye, Michel Pons, Management of vapor release in secondary refrigeration processes based on hydrates involving CO2 as guest molecule, International Journal of Refrigeration (2018), doi: https://doi.org/10.1016/j.jirefrig.2018.11.017

This is a PDF file of an unedited manuscript that has been accepted for publication. As a service to our customers we are providing this early version of the manuscript. The manuscript will undergo copyediting, typesetting, and review of the resulting proof before it is published in its final form. Please note that during the production process errors may be discovered which could affect the content, and all legal disclaimers that apply to the journal pertain. 
Management of vapor release in secondary refrigeration processes

based on hydrates involving $\mathrm{CO}_{2}$ as a guest molecule

Ziad Youssef $^{\mathrm{a}}$, Laurence Fournaison ${ }^{\mathrm{b}}$, Anthony Delahaye ${ }^{\mathrm{b}}$, and Michel Pons ${ }^{\mathrm{a}}$

a LIMSI, CNRS, Université Paris-Saclay, Rue du Belvédère bât 507, 91405 Orsay Cedex, France

b Irstea, UR GPAN, Refrigeration Process Engineering Research Unit, 1 Rue Pierre-Gilles de Gennes, F-92761 Antony, France

* Corresponding author: michel.pons@limsi.fr

\title{
Highlights
}

- Secondary refrigeration with gas hydrates requires special management of the released vapor

$\square$ This is the first published study of this issue, with rigorous mass and energy balances

$\square$ The storage volume is split into two tanks, one for the slurry, one for the vapor

$\square$ Vapor compression significantly reduces the volume of stored vapor

$\mathrm{CO} 2$ compression may also contribute to cold production

\begin{abstract}
When used as secondary refrigerants for cold storage and refrigeration applications, hydrate slurries offer/high-energy densities due to their significant latent heat of fusion. In this context, gas hydrates exhibit a feature not yet explored in the literature: vapor is released when hydrate crystals melt in the heat exchanger supplying cold to end users. This novel feature is investigated in this paper. First, the separation of the released vapor from the solidliquid slurry is described. This is followed by a study of how the design of the storage system can be adapted to the use of gas hydrate slurries as secondary fluid and specifically the consequences on its volume. A model is developed, based on energy and mass balances, to determine the required storage volume. Two types of hydrates involving a gas are considered:
\end{abstract}


the single hydrate of carbon dioxide and the mixed hydrate of tetra-n-butylphosphonium bromide (TBPB) plus $\mathrm{CO}_{2}$. The results show that adding vapor compression to the process can save up to $75 \%$ of the total storage volume.

\section{Keywords}

Phase Change Material, Slurry, Process optimization, Gas management, TBPB, Hydrate.

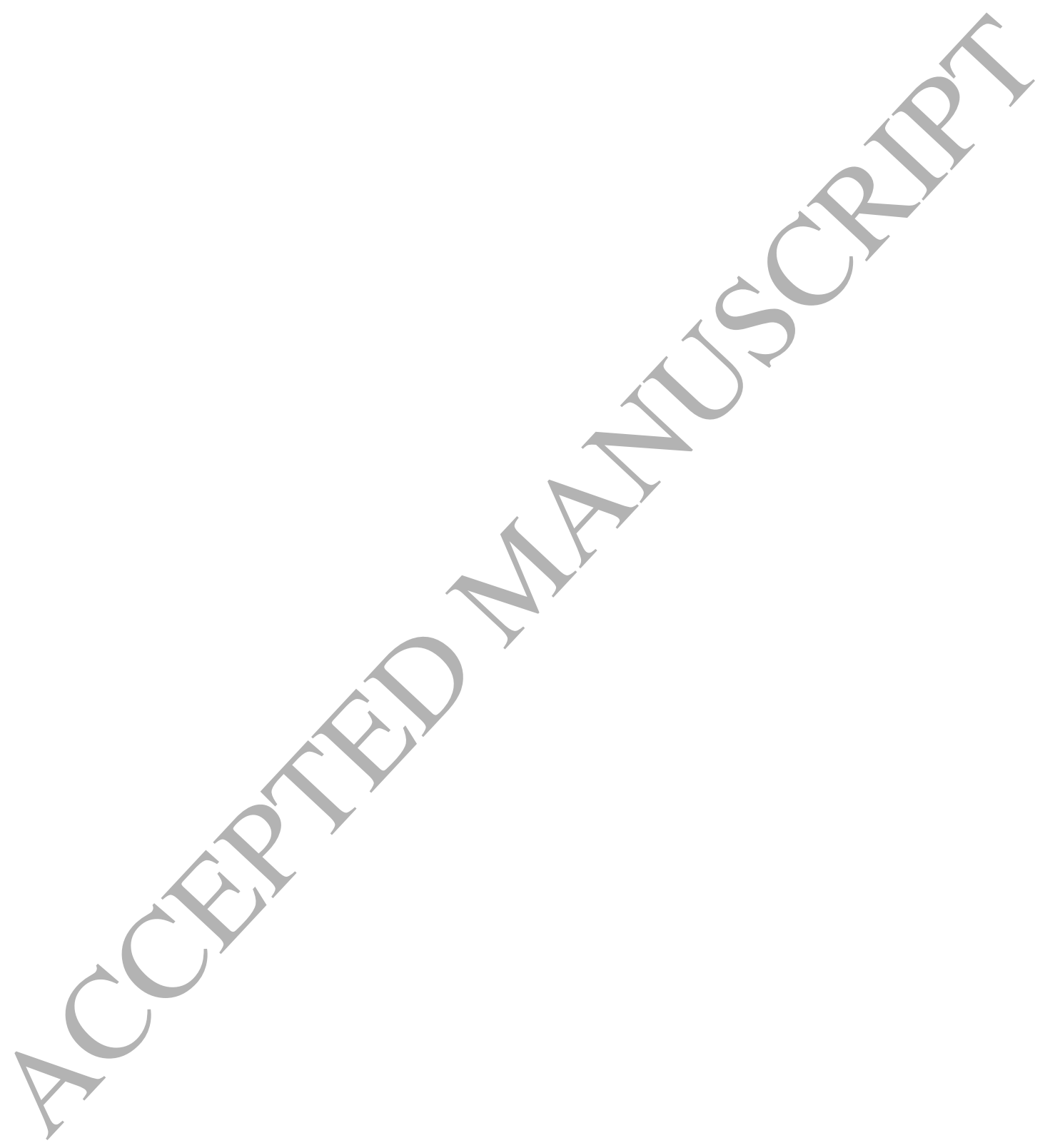




\section{Nomenclature}

Usual notations are not recalled (e.g. $T$ for temperature, $P$ for pressure, $m$ for mass, etc.).

$e$ specific internal energy $\left({\left.\mathrm{J} . \mathrm{kg}^{-1}\right)}^{-1}\right.$

Superscripts

$E$ internal energy (J)

$e$ evening

$\Delta H_{f}$ latent heat of fusion $\left({\left.\mathrm{J} . \mathrm{kg}^{-1}\right)}^{-1}\right.$

$m$ morning

$V$ volume $\left(\mathrm{m}^{3}\right)$

* moment when $P_{2}$ reaches $P_{1}^{e}$

$x$ additive fraction in its aqueous solution $\left(\mathrm{kg} . \mathrm{kg}^{-1}\right)$

Indexes

$x_{0}$ value of $x$ in the solution of TBPB when $X=0$ (without hydrate crystal) $\left({\mathrm{kg} . \mathrm{kg}^{-1}}^{-1}\right)$

$X$ solid mass fraction in the slurry $\left(\mathrm{kg} \cdot \mathrm{kg}^{-1}\right)$

$Y$ component fraction in the solid phase $\left(\mathrm{kg} \cdot \mathrm{kg}^{-1}\right)$

Greek symbols

$\eta_{i}$ isentropic compression efficiency (-)

$\sigma$ carbon dioxide solubility in the aqueous phase $\left(\mathrm{kg} \cdot \mathrm{kg}^{-1}\right)$

1,2 tank number

$A$ additive (TBPB)

$C$ carbon dioxide

$e q$ equilibrium

$f$ fusion

$L$ liquid phase

$S$ solid phase (crystals)

$T$ total

$V$ vapor phase

$W$ Water $\left(\mathrm{H}_{2} \mathrm{O}\right)$ 


\section{Introduction}

In response to the Kyoto Protocol and the rising concern about greenhouse gas emissions, there is a general consensus that the use of hydrofluorocarbons in refrigeration must be reduced. More environmentally friendly fluids are being introduced and the use of secondary refrigeration is being promoted (Cowan et al., 2010). The principle of secondary refrigeration consists of reducing the volume of the primary cooling unit (and therefore its leaks) as much as possible while using a secondary loop containing a safer fluid to distribute cooling power to users (Fournaison et al., 2004; Mota-Babiloni et al., 2015; Wang et al., 2010). Adding a cold storage system to the secondary loop may offer the advantage of enabling the cold produced by the primary unit to be supplied to users at a later time. Such secondary systems can be found in France in places such as the Hospices Civils de Lyon (Serre, 2016) and in Eaubonne near Paris (Compingt et al., 2009). This article is used here-under as a reference for comparison, its content is thus described with some more details. That cold storage and distribution system is installed in a hospital kitchen of $1750 \mathrm{~m}^{2}$ ) that distributes 4000 meals a day. The system extracts heat from 15 cold chambers (around $2^{\circ} \mathrm{C}$ ), four blast chiller shells, two low temperature chambers, cooling of the work space $\left(200 \mathrm{~m}^{2}\right)$, and air conditioning of the attached offices. Thanks to the storage, cold can be produced over a longer period than that of the peak demand: the primary cooling unit was then downsized at $234 \mathrm{~kW}$ (instead of $330 \mathrm{~kW}$ ). Moreover, cold production at night benefits from cheaper electricity and better cooling COP (the outdoor temperature is lower). The secondary and cold storage fluid is a slurry of ice in a solution of mono-propylene-glycol $\left(14 \%\right.$, freezing point $\left.-4.6{ }^{\circ} \mathrm{C}\right)$. The storage $\operatorname{tank}\left(67 \mathrm{~m}^{3}\right)$ is said "full" when it contains $30 \%$ of ice crystals at $-7^{\circ} \mathrm{C}$. In average, the kitchen consumes 19 tons of ice a day $(6.8 \mathrm{GJ})$.

The secondary fluid is either single-phase (chilled water, solution of glycol) or two-phase (a solid-liquid slurry). Ice slurries (as used in the latter two units) have been known about for a long time (Bellas and Tassou, 2005; Guilpart et al., 2005). They are operated at atmospheric pressure, and their energy density is attractive due to the latent heat of ice (Fournaison et al., 2004). However, new secondary fluids are emerging: clathrate hydrate slurries (Marinhas et al., 2007; Marinhas et al., 2006; Ogoshi and Takao, 2004; Youssef et al., 2013). Hydrates are ice-like compounds in which water molecules arrange around guest molecules such as carbon dioxide, hydrocarbons, or quaternary salts. Their formation temperature mostly lies above $0^{\circ} \mathrm{C}$ and, when present, the gas pressure may be above atmospheric (Sloan and Koh, 2008). Their latent heat of fusion is often lower than that of ice, except for the hydrate of $\mathrm{CO}_{2}$ (Fournaison 
et al., 2004; Jerbi et al., 2010; Kang et al., 2001; Marinhas et al., 2006; Yoon et al., 2003). Mixed hydrates may also form, associating a gas and a salt. Because of the wide variety of hydrates, plus the effect of gas pressure when present, the melting temperature can be tailored to the application for greater overall energy efficiency (Pons et al., 2015).

The potential presence of gas in secondary refrigeration processes with cold storage is thus a new feature. This article investigates the consequences of this presence of gas on the design of these types of systems. When gas hydrate crystals melt, they release vapor at the operating pressure of the secondary loop. The storage system must then be sized for storing this vapor before it is used again when new crystals are generated. To the best of our knowledge, there is no study in the literature dealing with such an issue. The system under consideration herein is designed for air-conditioning applications. It uses either the single hydrate of $\mathrm{CO}_{2}$ or the mixed hydrate of $\mathrm{CO}_{2}+$ TBPB (tetra-n-butylphosphonium bromide, a quaternary salt), referred to as $C O$ and $M H$ respectively. The $C O$ hydrate operates at high pressure (1-4MPa). The $M H$ hydrate operates at a much lower pressure (0.1-0.4MPa) but has a $40 \%$ lower latent heat of fusion (Mayoufi et al., 2010). A comparison of the two hydrates provides insight on the various effects involved.

First, this article describes how the process is adapted to this release of vapor and introduces two configurations. Next, the equations describing the mass, volume, and energy balances are described, followed by their numerical resolution. The results in terms of storage volume are then presented and compared to the system of Compingt et al. (2009). Finally, energy considerations are described for the most attractive configuration.

\section{Material and operation}

\subsection{Description of the system and material}

Generally speaking, the entire process has three functions: (i) primary cooling plus crystal generation, (ii) cold storage, and (iii) cold distribution via the secondary loop. Hydrate crystals are generated in a special heat exchanger cooled by the primary cooling unit. The design and operation alone of this heat exchanger are broad and complex issues that are worthy of a review and extensive analysis. This is far beyond the scope of this present article, which focuses on the storage system and the related aspects of the loop. Figure 1 presents the process flow diagram; the numbers in square brackets refer to it. The storage part is split into two tanks. Tank 1 [1] contains all the slurry plus a limited volume of vapor whereas Tank 2 [2] contains $\mathrm{CO}_{2}$ vapor only. In a first approach, the tanks are interconnected and the vapor 
pressure is uniform. This is denoted as Configuration $\mathrm{A}$ in the following. In the second configuration (denoted as "B"), the vapor contained in Tank 2 is eventually pressurized. Therefore, a valve [3], a compressor [4], and a heat exchanger [5] are implemented between the two tanks. The compressor pressurizes the $\mathrm{CO}_{2}$ vapor and the heat exchanger cools it using outside air.

The secondary slurry loop supplies cooling power to the various "users" (three users in Fig. 1). For each user, the slurry is circulated by a pump [8] across a heat exchanger [9] where crystals melt. When leaving the heat exchanger, the three-phase flow (slurry plus vapor released by hydrate fusion) enters a cyclone [10] where centrifugal forces and gravity separate the solid-liquid slurry, which is recovered at the bottom, from the $\mathrm{CO}_{2}$ vapor, which escapes at the top. The slurry returns to the secondary loop where it flows toward the next users and eventually to storage Tank 1 . The separated vapor is collected in a parallel circuit leading to Tank 1.

\subsection{Description of the operating procedure}

For the sake of clarity, the procedure described hereunder is based on nominal values of the operation variables and on the assumption that the rates of cold production at night and of cooling supply during the day are both steadily constant. The transition moments between these two operating modes are $t^{m}$ in the morning (when the storage is "full"), and $t^{e}$ in the evening (when the storage is "empty"). At these moments, the solid mass fraction in the slurry $X$ is $X^{m}$ (maximal) and $X^{e}$ (minimal) and the vapor pressure in Tank $j\left(j=1\right.$ or 2 ) is $P_{j}^{m}$ (minimal) and $P_{j}^{e}$ (maximal). Elision of the index $j$ means that $P_{1}=P_{2}$. All the equations here-under consider the possibility of a non-zero value of $X^{e}$, but all the calculations are done with $X^{e}=0$.

\subsubsection{Daytime: Supplying cooling to users}

The melting of hydrate crystals in the heat exchangers releases liquid water, additive (TBPB) when present, and carbon dioxide. The proportion of liquid in the slurry increases and the composition of this phase changes due to the addition of water and TBPB. Meanwhile, part of the released $\mathrm{CO}_{2}$ is dissolved into the liquid phase and the other part turns into vapor. As the entire system is closed, this extra vapor causes the pressure to increase in the whole circuit, storage tanks plus secondary loop. Consequently, the temperature of the three-phase system 
increases according to the thermodynamic equilibrium conditions. This is true for both slurries $C O$ and $M H$. For the $M H$ slurry, the melting crystals also increase the additive concentration in the liquid phase (TBPB concentration is greater in the hydrate than in the liquid solution). This also raises the equilibrium temperature. As a result, the temperature of the slurry in Tank 1 increases throughout the day, thus adding a non-negligible contribution by sensible heat to the cold storage process. The increase in vapor pressure has another consequence: the amount of $\mathrm{CO}_{2}$ dissolved in the liquid phase increases $\left(\mathrm{CO}_{2}\right.$ solubility is almost proportional to pressure), which reduces the amount of $\mathrm{CO}_{2}$ stored as vapor.

Figure 2 shows the pressure changes in either tank for Configurations $A$ and $B$. In Configuration A (solid lines), the vapor pressure is the same in both tanks and the operating procedure is very simple. Between moments $t^{m}$ and $t^{e}$, the vapor pressure increases from $P^{m}$ to $P^{e}$ and the slurry temperatures rise from $T_{1}^{m}$ to $T_{1}^{e}$. It is assumed that $P^{e}$ equals $P_{1}^{e}$, which is the upper limit value for pressure in Tank 1.

In Configuration B (dashed lines in Fig. 2), the vapor stored in Tank 2 is pressurized so that the volume $V_{2}$ of this tank can be reduced. Consequently, the same thermal conditions as above produce a much faster pressure increase after $t^{m}$. The limit pressure $P_{1}^{e}$ is then reached well before $t^{e}$, at the moment denoted as $t^{*}$. After $t^{*}$, the pressure $P_{1}$ is controlled and remains constant while any new amount of $\mathrm{CO}_{2}$ vapor generated by crystal melting is pressurized and directed to Tank 2 by the compressor [4]. The pressure $P_{2}$ thus continues to rise and reaches its upper limit value $P_{2}^{e}$ at $t^{e}$ when the cold storage is "empty" $\left(X=X^{e}\right)$.

\subsubsection{Nighttime: Hydrate crystal generation and storage}

At night, between $t$ and the next $t^{m}$, the heat exchanger for crystal generation is supplied with slurry drawn from Tank 1 plus $\mathrm{CO}_{2}$ vapor extracted from Tank 2 while being cooled by the primary unit. The hydrate crystals produced from this process are transported by the slurry and returned to Tank 1 where the average solid mass fraction $X$ increases from $X^{e}$ to $X^{m}$. Meanwhile, the vapor pressure in Tank 2 falls to $P^{m}$. In Configuration A (solid lines in Fig. 2), the vapor pressure decreases equally in both tanks. In Configuration B (dashed lines), the tanks are separated by the valve [3] as long as $P_{2}$ lies above $P_{1}$; they are interconnected 
once both pressures are equal. When the cold storage is "full" $\left(X=X^{m}, P_{1}=P_{2}=P_{1}^{m}\right)$, a new cycle can begin.

\section{Numerical model}

The equations are developed hereunder for the $M H$ slurry with water $(W), \mathrm{CO}_{2}(C)$, and TBPB additive $(A)$. The $C O$ slurry is simply a case without additive. In a similar problem, Marinhas et al. (2007) derived the solid mass fraction in the slurry from the vapor pressure in a closed vessel of a given volume. The present problem couples mass and volume conservation to the energy balance so that a prescribed amount of "cold" is stored. Thus, the respective amounts of water, $\mathrm{CO}_{2}$ and additive, and the volumes of either tanks are unknown values that must be calculated in order to address constraints on energy and pressure.

\subsection{Mass balances in the three-phase system}

Mass balances are established for each phase $S, L$, and $V$, and each material $W, C$, and $A$. These notations can be combined. For example, $m_{W, L}$ refers to the mass of water in the liquid phase. Water and additive only exist in the solid and liquid phases: $m_{\bullet}=m_{\bullet, S}+m_{\bullet, L}, \bullet \in\{W, A\}$. Carbon dioxide exists in each phase: solid, liquid (where it dissolves), and vapor (where it is the only component): $m_{C}=m_{C, S}+m_{C, L}+m_{V}$. The stoichiometry of the solid phase is written as: $m_{\bullet, S}=Y_{\bullet} \cdot m_{S}, \bullet \in\{W, A, C\}$, with $\sum_{\bullet} Y_{\bullet}=1$. The liquid phase consists of water plus dissolved $\mathrm{CO}_{2}$, plus additive for the mixed hydrate. The $\mathrm{CO}_{2}$ solubility $\sigma=m_{C, L} /\left(m_{C, L}+m_{W, L}\right)$ and the fraction of additive in the aqueous solution $x=m_{A, L} /\left(m_{A, L}+m_{W, L}\right)$ can respectively be rewritten as: $m_{C, L}=m_{W, L} \cdot \sigma /(1-\sigma)$ and $\quad m_{A, L}=m_{W, L} \cdot x /(1-x)$. Combination with the liquid mass budget $m_{L}=m_{W, L}+m_{C, L}+m_{A, L}$ results in:

$$
m_{W, L}=m_{L} \cdot \frac{(1-x) \cdot(1-\sigma)}{1-x \cdot \sigma}
$$

Where $x_{0}$ denotes the fraction of additive in its solution in water (no crystal, no $\mathrm{CO}_{2}$ ), $x_{0}=m_{A} /\left(m_{A}+m_{W}\right)$, one has: $\left(1-x_{0}\right) \cdot m_{A}=x_{0} \cdot m_{W}$, which is easily rewritten as $\left(1-x_{0}\right) \cdot\left(m_{A, S}+m_{A, L}\right)=x_{0} \cdot\left(m_{W, S}+m_{W, L}\right)$. Using $m_{\bullet, S}=Y_{\bullet} \cdot m_{S}$ and the expressions of $m_{\bullet, L}$ above, this equation becomes: 


$$
\left(1-x_{0}\right) \cdot\left[Y_{A} \cdot m_{S}+\frac{x \cdot(1-\sigma)}{1-x \cdot \sigma} \cdot m_{L}\right]=x_{0} \cdot\left[Y_{W} \cdot m_{S}+\frac{(1-x) \cdot(1-\sigma)}{1-x \cdot \sigma} \cdot m_{L}\right]
$$

When introducing the solid fraction in the slurry, $X=m_{S} / m_{S L}=1-m_{L} / m_{S L}$, the equation becomes:

$$
\left(1-x_{0}\right) \cdot\left[Y_{A} \cdot X+\frac{x \cdot(1-\sigma)}{1-x \cdot \sigma} \cdot(1-X)\right]=x_{0} \cdot\left[Y_{W} \cdot X+\frac{(1-x) \cdot(1-\sigma)}{1-x \cdot \sigma} \cdot(1-X)\right]
$$

Simple albeit tedious algebra then results in the following expression of the fraction $x$ :

$$
x=\frac{x_{0} \cdot(1-\sigma) \cdot(1-X)+X \cdot\left[x_{0} \cdot\left(Y_{A}+Y_{W}\right)-Y_{A}\right]}{(1-\sigma) \cdot(1-X)+\sigma \cdot X \cdot\left[x_{0} \cdot\left(Y_{A}+Y_{W}\right)-Y_{A}\right]}
$$

In hour-long processes, the slurry may be assumed to be in full equilibrium. Therefore, the fraction of $\mathrm{CO}_{2}$ dissolved in water is given by its equilibrium function $\sigma=\sigma_{e q}(P, T)$, depending on $\mathrm{CO}_{2}$ pressure and solution temperature (Diamond and Akinfiev, 2003), and the latter temperature is given by the equation of state $T=T_{e q}(P, x)$. Lastly, the densities of the slurry and $\mathrm{CO}_{2}$ vapor $\left(\rho_{S L}\right.$ and $\left.\rho_{V}\right)$ can also be evaluated from the compositions $x$ and $X$, pressure and temperature, which leads to the concern at hand: the volume occupied by the entire system, $V_{T}=m_{S L} / \rho_{S L}+m_{V} / \rho_{V}$.

The thermophysical data $Y_{\bullet}$ and the functions $\sigma_{e q}, T_{e q}, \rho_{S L}$ and $\rho_{V}$ used in the calculations are described in the Appendix A.

\subsection{Volume conservation}

As the entire system is closed, its volume is always the same, especially at $t^{m}$ and $t^{e}$. Tank 1 , with volume $V_{1}$, contains the whole slurry plus a small amount of $\mathrm{CO}_{2}$ vapor. Tank 2 , with volume $V_{2}$, only contains the rest of vapor; its pressure and temperature (and gas density) may differ from those in Tank 1 (see Section 2). These statements are written as

$$
V_{1}=\frac{m_{S L}}{\rho_{S L}}+\frac{m_{V 1}}{\rho_{V 1}} ; \quad V_{2}=\frac{m_{V 2}}{\rho_{V 2}} ; \text { with } m_{V 1}+m_{V 2}=m_{V}
$$

The extra volume of vapor in Tank 1 enables the slurry to expand if needed (the slurry may expand by $2.5 \%$ with the mixed hydrate, but it shrinks slightly with the single hydrate). It also enables the implementation of gas connections with the cold distribution loop and with Tank

2 (see Fig. 1). It is stated herein that $V_{1}=1.05 \times m_{S L}^{m} / \rho_{S L}^{m}$, i.e. $5 \%$ more than the volume 
occupied by the slurry at $t^{m}$. This value of 5\% was approved by an industrial partner (Serre, 2016); a lower value (e.g. $2 \%$ ) would hardly change the storage volume (the amount of $\mathrm{CO}_{2}$ must anyhow be stored in either tank), and a larger value (e.g. 10\%) would be oversized. Once the volume of Tank 1 has been sized, the volume of Tank 2 is given by the equation $V_{2}=m_{V}^{m} / \rho_{V}^{m}-\left(V_{1}-m_{S L}^{m} / \rho_{S L}^{m}\right)$.

Given the amount of vapor contained in Tank 1 at moment $t^{e}, m_{V 1}^{e}=\rho_{V 1}^{e} \cdot\left(V_{1}-m_{S L}^{e} / \rho_{S L}^{e}\right)$, and that the rest of vapor is contained precisely in Tank 2, i.e. that $\rho_{V 2}^{e} \cdot V_{2}=m_{V}^{e}-m_{V 1}^{e}$, the volume conservation equation for the entire system is:

$$
\left.\rho_{V 2}^{e} \cdot\left(\frac{m_{V}^{m}}{\rho_{V}^{m}}-V_{1}+\frac{m_{S L}^{m}}{\rho_{S L}^{m}}\right)=m_{V}^{e}-\rho_{V 1}^{e} \cdot\left(V_{1}-\frac{m_{S L}^{e}}{\rho_{S L}^{e}}\right)\right)
$$

\subsection{Energy balance}

The energy balance states that between moments $t^{m}$ and $t^{e}$, the storage system receives the heat quantity $Q$ extracted from the users' heat exchangers plus the energy resulting from vapor compression and cooling when Configuration B is considered. A posteriori evaluations of the heat input through the thermal insulation of the storage tanks show that this effect is comparable to those of compression in the worst cases (too large volumes) and negligible in the most likely cases (see Appendix B1).

Similarly, evaluations of the volume of the cold-distribution loop show that it represents only one or two percent of the total (see Appendix B2). It can then be stated that Tank 1 contains the whole slurry. Moreover, the whole circuit is closed, it absorbs heat, and work is done on it. For closed systems, the First Law states a balance of internal energy: $\mathrm{d} e=\delta q+\delta w$ (enthalpy balances hold for open systems). The total internal energy involves the solid and liquid phases, phase change, and the vapor. The liquid and solid phases of the slurry are incompressible, with equal $c_{p}$ and $c_{v}$. The internal energy of the solid and liquid phases depends only on temperature: $\mathrm{d} E_{S L}=\left(m_{S} \cdot c_{p S}+m_{L} \cdot c_{p L}\right) \cdot \mathrm{d} T$. The contribution of phase change to total internal energy is: $\mathrm{d} E_{f}=\Delta H_{f} \cdot\left(-\mathrm{d} m_{S}\right)$, where $-\mathrm{d} m_{S}$ is the elementary amount of melted crystal. As the $\mathrm{CO}_{2}$ vapor is a compressible non-ideal gas, the contribution of volume change to internal energy cannot be overlooked. The elementary change in internal 
energy is conveniently written as: $\mathrm{d} e_{V}=c_{\nu V} \cdot \mathrm{d} T+\left(\partial e_{V} / \partial \rho\right)_{T} \cdot \mathrm{d} \rho_{V}$. Combining the wellknown partial derivative $\left[\partial e_{V} / \partial\left(\rho^{-1}\right)\right]_{T}=T \cdot(\partial P / \partial T)_{\rho}-P$, with the van der Waals equation of state where $(\partial P / \partial T)_{\rho}=\left(P+a . \rho^{2}\right) / T$, one obtains: $\mathrm{d} e_{V}=c_{v V} \cdot \mathrm{d} T-a \cdot \mathrm{d} \rho_{V}$. After summing up these three contributions, the elementary change of total internal energy is:

$$
\mathrm{d} E=\left[\begin{array}{l}
\Delta H_{f} \cdot\left(-\mathrm{d} m_{S}\right)+\left(m_{S} \cdot c_{p S}+m_{L} \cdot c_{p L}+m_{V 1} \cdot c_{v V 1}\right) \cdot \mathrm{d} T_{1} \\
-a \cdot m_{V 1} \cdot \mathrm{d} \rho_{V 1}+m_{V 2} \cdot\left(c_{v V 2} \cdot \mathrm{d} T_{2}-a \cdot \mathrm{d} \rho_{V 2}\right)
\end{array}\right]
$$

where the difference between the vapor contained in Tank 1 and that contained in Tank 2 is introduced. The moment when the vapor pressure, equal in both tanks, reaches $P_{1}^{e}=P_{1}=P_{2}$ is denoted by the superscript $*\left(X=X^{*}\right.$ and $T_{1}=T_{2}=T^{*}$, see Fig. 2); it separates two different integrations of eq. (4): (i) from $t^{m}$ to $t^{*}$ with the same vapor pressure in both tanks, (ii) from $t^{*}$ to $t^{e}$ with different vapor states in either tank.

Between $t^{m}$ and $t^{*}$, the amount of melted crystal is $-\Delta m_{S}^{m^{*}}=m_{S L}^{m} \cdot X^{m}-m_{S L}^{*} \cdot X^{*}$ and the change of internal energy

$$
\Delta E^{m^{*}}=\Delta H_{f} \cdot\left(-\Delta m_{S}^{m^{*}}\right)+\int_{m}^{*}\left(m_{S} \cdot c_{p S}+m_{L} \cdot c_{p L}+m_{V} \cdot c_{v V}\right) \cdot \mathrm{d} T-a \cdot \int_{m}^{*} m_{V} \cdot \mathrm{d} \rho_{V}
$$

is due only to the heat flux coming from the users (there is no compression work during this period). In Configuration A, there is no difference between the moments $t^{*}$ and $t^{e}$ and one has $\Delta E^{m^{*}}=Q$. The latter equality holds when the heat input through thermal insulation of the storage tanks can be neglected, an assumption justified in Appendix B.

In Configuration $\mathrm{B}$, the moment $t^{*}$ occurs much earlier than $t^{e}$. Between $t^{*}$ and $t^{e}$, the amount of melted crystal is $-\Delta m_{S}^{* e}=m_{S L}^{*} \cdot X^{*}-m_{S L}^{e} \cdot X^{e}$, and the increase in internal energy is

$$
\Delta E^{* e}=\left[\begin{array}{l}
\Delta H_{f} \cdot\left(-\Delta m_{S}^{* e}\right)+\int_{*}^{1 e}\left(m_{S} \cdot c_{p S}+m_{L} \cdot c_{p L}+m_{V} \cdot c_{v V}\right) \cdot \mathrm{d} T-a \cdot \int_{*}^{1 e} m_{V} \cdot \mathrm{d} \rho_{V} \\
+\int_{1 e}^{2 e} m_{V 2} \cdot c_{v V 2} \cdot \mathrm{d} T_{2}-a \cdot \int_{1 e}^{2 e} m_{V 2} \cdot \mathrm{d} \rho_{V 2}
\end{array}\right]
$$

Equation (5) is written as if the operation from $t^{*}$ to $t^{e}$ were done in two steps. First, there is the melting of crystals with Tank 2 being large enough to contain all the released $\mathrm{CO}_{2}$ at pressure $P_{1}^{e}$. Next, the vapor contained in Tank 2 is pressurized and cooled down, thus 
reaching the state $\left(P_{2}^{e}, T_{2}^{e}\right)$. As $P^{*}$ equals $P_{1}^{e}$, the difference $T^{*}-T_{1}^{e}$ either vanishes for the single hydrate $C O$ or equals one or two Kelvin for the mixed hydrate $M H$. In other words, the first line of (5) is only powered by the heat input from the users, while the second line only applies to the compression plus cooling of the vapor contained in Tank 2 . The sum of $\Delta E^{m *}$ and of the first line of $\Delta E^{* e}$ then equates the total heat extracted from the users:

$$
\Delta H_{f} \cdot\left(-\Delta m_{S}^{m e}\right)+\int_{m}^{1 e}\left(m_{S} \cdot c_{p S}+m_{L} \cdot c_{p L}+m_{V} \cdot c_{v V}\right) \cdot \mathrm{d} T-a \cdot \int_{m}^{1 e} m_{V} \cdot \mathrm{d} \rho_{V}=Q .
$$

Since the contribution of the vapor phase (sensible heat plus compression effect) is by far the smallest contribution, this equation can be simplified as:

$$
\left[\begin{array}{l}
\Delta H_{f} \cdot\left(-\Delta m_{S}^{m e}\right)-a \cdot \overline{m_{V}} \cdot\left(\rho_{V 1}^{e}-\rho_{V}^{m}\right) \\
+\left(\overline{m_{S} \cdot c_{p S}}+\overline{m_{L} \cdot c_{p L}}+\overline{m_{V} \cdot c_{v V}}\right) \cdot\left(T_{1}^{e}-T^{m}\right)
\end{array}\right]=Q
$$

where all quantities with an overbar are averaged between $t^{m}$ and $t^{e}$. The values of $c_{p S}$ and $c_{p L}$ and the equation of state of $\mathrm{CO}_{2}$ used herein are described in the Appendix A.

\subsection{Resolution}

For the slurry, the $\mathrm{CO}_{2}$ pressure and solid fraction at $t^{m}$ and at $t^{e}, P^{m}, P_{1}^{e}, X^{m}$ and $X^{e}$, are design parameters that are directly related to the temperature range at which the cooling power is delivered to the users. The maximal pressure $P_{2}^{e}$ and the initial additive fraction $x_{0}$ are also design parameters. Once all these variables are given, only one set of masses $\left(m_{W}\right.$, $m_{C}$ ) can precisely store the heat quantity $Q$ under the given conditions (3) and (6). It should be noted that some $\mathrm{CO}_{2}$ always remains in the vapor volume. All the other masses can then be calculated, followed by the volumes of the two tanks. The whole problem is solved iteratively in the Matlab ${ }^{\circledR}$ environment. The study now focuses on the influence of the value $X^{m}$ selected as the solid mass fraction in the morning.

\section{Results and discussion}

\subsection{Operating conditions}

The application considered herein is air conditioning. The design parameters aim to find a trade-off between a minimal size of the storage tanks and a pressure in the circuit that is not 
excessively high. The two tanks are sized for storing the same energy as reported by Compingt et al. (2009): 6.8GJ (1.9MWh). Four cases are explored: two with the $C O$ slurry (CO_I and CO_II) and two with the $M H$ one (MH_I and $\left.\mathrm{MH} \_\mathrm{II}\right)$ for which the $\mathrm{CO}_{2}$ pressure is lower by about one order of magnitude. The difference $\left(T^{e}-T^{m}\right)$ is kept the same as in the reference case (Compingt et al., 2009), 2.4K, or close to it. The cases CO_I and CO_II differ by their average temperature $\left(2.8\right.$ and $\left.8.2^{\circ} \mathrm{C}\right)$, which were selected for protecting the system against icing (CO_I) or $\mathrm{CO}_{2}$ condensation (CO_II). The corresponding values of pressure are presented in Table 1. The two cases with $M H$ keep the same average temperature as in case CO_II, but the difference $\left(T^{e}-T^{m}\right)$ is set to $4 \mathrm{~K}\left(\mathrm{MH} \_\mathrm{I}\right)$ and $6 \mathrm{~K}(\mathrm{MH}$ II $)$ in order to avoid huge volumes for Tank 2 due to limited values of the pressure difference $P_{1}^{e}-P^{m}$.

In Configuration B the vapor is pressurized at $P_{2}^{e}=8 \mathrm{MPa}$ for the $C O$ cases and $4 \mathrm{MPa}$ for the $M H$ cases. The paths followed by the $\mathrm{CO}_{2}$ vapor during compression and subsequent cooling are described and commented in section 4.3. For the $M H$ cases, the additive fraction in the liquid before contact with $\mathrm{CO}_{2}, x_{0}$, is 0.2 . The cold storage is said to be "empty" when there is no more solid phase left $\left(X^{e}=0\right)$. The solid fraction in full storage, $X^{m}$, is investigated within the range [0.26 - 0.38]. The results here-under show that values of $X^{m}$ below 0.26 lead to quite large storage volumes: this range has thus not been investigated any further. Values of $X^{m}$ above 0.30 are usually seen as potentially problematic because of the risk of flow blocking. This range was however investigated up to 0.38 in order to evaluate the possible benefits of high $X^{m}$ values.

\subsection{Results for Configuration A}

Figure 3 presents the calculated volumes for Tank 1 and for both tanks (total). In the reference case, the storage volume was $67 \mathrm{~m}^{3}$ with $X^{m}=0.30$. The volume of Tank 1 is roughly similar, but the total volume is dramatically larger, particularly when the final pressure $P^{e}$ is relatively low (cases CO_I and MH_I).

\subsubsection{Volume of Tank 1: Analysis}

The trends and differences observed in Figure 3 can be interpreted as follows. First, the volume of Tank 1 decreases when $X^{m}$ is increased. Indeed, most of the stored energy consists of latent heat, which can be written as: $Q \approx\left(-\Delta m_{S}\right) \cdot \Delta H$. In addition, and given that the 
mass of slurry $m_{S L}$ changes very little, it is possible to write $\left(-\Delta m_{S}\right) \approx \overline{m_{S L}} \cdot\left(X^{m}-X^{e}\right)$. The average amount of slurry $\overline{m_{S L}}$ can then be approximated as:

$$
\overline{m_{S L}} \approx \frac{Q}{\Delta H \cdot\left(X^{m}-X^{e}\right)}
$$

The volume of Tank 1, which contains all the slurry, is a decreasing function of $\left(X^{m}-X^{e}\right)$. For the $C O$ hydrate, the volume of Tank 1 is comparable to the $67 \mathrm{~m}^{3}$ reported by Compingt et al. (2009). With a latent heat of fusion $40 \%$ less than that of the single hydrate (see Appendix A), the mixed $M H$ hydrate requires a volume $44 \%$ larger. This proportion is reduced to $32 \%$ for the MH_II case, which involves more sensible heat than the others due to the larger value of $\left(T^{e}-T^{m}\right): 6 \mathrm{~K}$ instead of 4 or 2.4 (see Table 1$)$.

\subsubsection{Volume of Tank 2: Analysis}

The volume of Tank 2 depends primarily on the amount of $\mathrm{CO}_{2}$ released by crystal fusion and on the pressure difference $\left(P^{e}-P^{m}\right)$. The amount of released $\mathrm{CO}_{2}$ is $\left(-\Delta m_{C S}\right)=\left(-\Delta m_{S}\right) \cdot Y_{C}$. Table 2 gives the values of $\left(-\Delta m_{S}\right)$ and $\left(-\Delta m_{C S}\right)$. Some of this is dissolved in the liquid phase of the slurry $\left(\Delta m_{C L}\right)$, while the rest remains as vapor $\left(\Delta m_{V}\right)$. Given that $\mathrm{CO}_{2}$ solubility in water is almost proportional to vapor pressure (Diamond and Akinfiev, 2003), the amount $\Delta m_{C L}$ is nearly proportional to $\overline{(1-X) \cdot m_{S L}} \cdot\left(P^{e}-P^{m}\right)$. The effect of pressure difference $\left(P^{e}-P^{m}\right)$ on $\Delta m_{C L}$ can be seen in Table 2 , but the total mass of slurry $\overline{m_{S L}}$ also plays a role. As the amount of $\mathrm{CO}_{2}$ vapor in Tank 1 is small, the amount of $\mathrm{CO}_{2}$ stored in Tank 2, $\Delta m_{V 2}$, is close to $\left[\left(-\Delta m_{C S}\right)-\Delta m_{C L}\right]$ (see Table 2). The volume of Tank 2 is given by $\Delta m_{V 2} / \rho_{V 2}^{e}$, where the vapor density $\rho_{V 2}^{e}$ is highly dependent on the value of $P_{2}^{e}$ (see Table 2). A high value of vapor pressure at $t^{e}$ therefore reduces vapor volume in two ways: it increases both the mass of dissolved $\mathrm{CO}_{2}$ and the vapor density. Finally, the aforementioned decrease of $\overline{m_{S L}}$ when $X^{m}$ increases reduces the amount of $\mathrm{CO}_{2}$ dissolved, $\Delta m_{C L}$, and results in an increased volume for Tank 2, particularly when vapor pressure is low (cases $M H$ in Fig. 3). 


\subsection{Results for Configuration B}

\subsubsection{Tank volumes}

In order to reduce the volume of Tank 2, Configuration B considers pressurization of the vapor contained in this tank. Figure 4 shows the volumes calculated for this configuration. Compared to Configuration A, the volumes of Tank 1 (left vertical axis) are unchanged, but those of Tank 2 are reduced drastically through vapor compression (from $100-200 \mathrm{~m}^{3}$ to 20 $30 \mathrm{~m}^{3}$ ). The total volumes (right vertical axis) now follow the main downward trend in comparison to $X^{m}$. In the $C O$ cases, the total volume may still be very close to the reference volume of Compingt et al. (2009) when assuming larger values of $X^{m}(0.36$ herein instead of 0.30). The $C O$ cases are also characterized by a high operating pressure: between 2 and $4 \mathrm{MPa}$ for Tank 1 and up to $8 \mathrm{MPa}$ for Tank 2. Although the $M H$ cases lead to average volumes that are $25-30 \%$ larger than with $C O\left(93 \mathrm{~m}^{3}\right.$ in average instead of 75$)$, they still deserve consideration because they operate at much lower pressures than with $C O$ : approximately $0.5 \mathrm{MPa}$ for Tank 1 and $4 \mathrm{MPa}$ only for Tank 2 . Overall economic considerations will be decisive for selecting between these various solutions.

\subsubsection{Energy costs}

Aside from volume reduction, the impact of compression plus cooling by outdoor air on the overall energy budget also must be evaluated. There are two issues to take into consideration: the first is the mechanical energy required for compression and the second is the potential extra charge for the primary cooling unit. For both issues, the amount of $\mathrm{CO}_{2}$ processed from the state $\left(P_{1}^{e}, T_{1}^{e}\right)$ to the state $\left(P_{2}^{e}, T_{2}^{e}\right)$ equals the amount flowing through the compressor PLUS the vapor already contained in Tank 2 at $t^{*}$, i.e. the total content of Tank 2 at $t^{e}, m_{V 2}^{e}$. Once again, balances of internal energy are considered. The mechanical work of compression is calculated as: $W_{\text {comp }}=m_{V 2}^{e} \cdot \Delta e_{i} / \eta_{i}$, where the isentropic change of internal energy, $\Delta e_{i}$, is deduced from the corresponding changes in enthalpy and density read on the isentropic paths presented in Fig. 5, and where $\eta_{i}$ is the compressor's isentropic efficiency with $\eta_{i}=0.75$. Those compression paths lead to temperatures that are fairly high, from which it is easy to exchange heat with outdoor air, down to $T_{2}^{e}$ as presented in Fig. 5. Considering an outdoor temperature of $40^{\circ} \mathrm{C}$, which is a likely value in periods when people need air-conditioning, the chosen value for $T_{2}^{e}$ is $50^{\circ} \mathrm{C}$. Once again, the corresponding change in internal energy, i.e. the 
heat quantity exchanged with outdoor air $Q_{H X 2}$, is evaluated from the data displayed in this diagram. The final overall impact on the primary cooling demand, $\Delta Q=W_{c o m p}+Q_{H X 2}$, depends solely on the design parameters $\left(P_{1}^{e}, T_{1}^{e}\right)$ and $\left(P_{2}^{e}, T_{2}^{e}\right)$ (the crosses and closed circles in Fig. 5), not on the details of the compression process. The numerical results are given in Table 3.

With a mechanical work $W_{\text {comp }}$ lying between 2 and 5\% of the stored energy, the concept of vapor compression does not induce unbearable energy costs and the values of $\Delta Q$ show that the global impact on primary cooling demand is very weak. Moreover, the value given to $T_{2}^{e}$ $\left(50^{\circ} \mathrm{C}\right)$ considers operation in summer conditions. During the rest of the year, the $\mathrm{CO}_{2}$ vapor may be cooled to lower values; the quantity $\Delta Q$ would then become negative. Values of $\Delta Q$ calculated with $T_{2}^{e}=20^{\circ} \mathrm{C}$ are also reported in Table 3: while quite small in the $M H$ cases, they are not insignificant in the $C O$ cases. This is because the compression pressure $P_{2}^{e}$ is slightly supercritical in the $C O$ cases and not in the $M H$ cases and because the critical temperature (31.06) lies precisely within the temperature range under consideration [20$50^{\circ} \mathrm{C}$ ]. Just above the critical point, a limited temperature shift generates significant changes in enthalpy and internal energy. Consequently, the procedure described herein may contribute to the overall cold production in the $C O$ cases, potentially by $10 \%$. The marginal COP of this extra cold production, $\left(-\Delta Q / W_{\text {comp }}\right)$, would be 2 in the case CO_I, but close to 6 in the case CO_II. This is more efficient than most primary cooling units. Ogawa et al. (2006) have already proposed a cooling process entirely based on this principle, but which uses hydrates of fluorocarbon refrigerants (R290, R32, R134a and R152a). Using $\mathrm{CO}_{2}$ hydrates probably merits further investigation, particularly when considering that the technology of supercritical cooling cycles has already been developed.

\section{Conclusion}

The use of gas hydrates in secondary refrigeration processes equipped with cool storage has many consequences that are as yet unexplored. First, the vapor released by crystal fusion must somehow be separated from the liquid-solid slurry, probably in a separate circuit. Second, this vapor will be stored separately. When the entire system is operated under limited pressure (mixed hydrates without compression), this storage requires very significant volumes 
(between 200 and $300 \mathrm{~m}^{3}$ for storing 6.8GJ). Operation under high pressure, either because of the hydrate system (single hydrate of $\mathrm{CO}_{2}$ ) or through vapor compression, significantly reduces the storage volume (potentially down to $75 \mathrm{~m}^{3}$ ). With the single $\mathrm{CO}_{2}$ hydrate plus compression, the storage volume becomes similar to the $67 \mathrm{~m}^{3}$ required with ice slurries. In terms of energy, compression remains within the range of auxiliary costs (the energy consumed by compression represents between 2 and $4 \%$ of the total stored energy). It also occurs that, with the $\mathrm{CO}_{2}$ hydrate, compression plus cooling may contribute very efficiently to the overall cold production (by up to $10 \%$ with a marginal COP potentially above 4). Industrial developments will determine whether these advantages sufficiently compensate for the disadvantages of high pressure.

\section{Acknowledgment}

This work is part of the research project CRISALHYD \# ANR-14-CE05-0045 funded by the French ANR. It has also been developed in the framework of the GdR2026 HYDRATES DE $G A Z$ of CNRS. Moreover, the authors express their gratitude to Patrice Serre (LENNOX EMEA) for the valuable information he provided. 


\section{Appendix A: Equations of state and thermophysical properties}

The aim of this appendix is to provide a brief summary of the values or simplified correlations used in the computations, introducing $\pi=P / P_{0}$ with $P_{0}=1 \mathrm{MPa}$ as a non-dimensional variable and the temperature $\theta$ in Celsius.

\section{Equations of state}

The $\mathrm{CO}_{2}$ solubility $\sigma$ in the aqueous solution is described by a function that was adjusted based on the data of Diamond and Akinfiev (2003):

$$
\sigma(T, P)=\frac{m_{C, L}}{m_{C, L}+m_{W, L}}=\frac{\mathrm{A}_{\sigma} \cdot \pi^{2}+\mathrm{B}_{\sigma} \cdot \pi}{1+0.5907 \cdot\left(\mathrm{A}_{\sigma} \cdot \pi^{2}+\mathrm{B}_{\sigma} \cdot \pi-1\right)}
$$

where $\mathrm{A}_{\sigma}=-0.121+0.005 \cdot \theta$, and $\mathrm{B}_{\sigma}=1.38-0.04 \cdot \theta$.

For the single $\mathrm{CO}_{2}$ hydrate, the equilibrium temperature depends only on the gas pressure. The data of Yang et al. (2000) and Jerbi et al. (2010) are linearized in the range of interest according to: $\theta_{e q}(\pi)=7.19 \cdot \operatorname{Ln}(\pi)-0.705$.

For the mixed hydrate, an equation of state of the form: $\theta_{e q}(\pi, x)=B /[A(x)-\operatorname{Ln}(\pi)]-273.15$, was adjusted according to the experimental data published by Ilani-Kashkouli et al. (2016); Mayoufi et al. (2011); Shi et al. (2013); Zhang et al. (2013), with $B=24520 \quad$ and $A(x)=85.49+60.85 \cdot \delta x^{2.328} \cdot\left(1-8.067 \cdot \delta x+27.55 \cdot \delta x^{2}\right)$ with $\delta x=0.3-x$.

\section{Density and heat capacity}

The specific volume and heat capacity of the slurry are linear combinations of those of each phase: $\bullet_{S L}=X \cdot \bullet_{S}+(1-X) \cdot \bullet L$, where $\bullet \in\left\{c_{p}, \rho^{-1}\right\}$. The values of $c_{p}$ or $\rho$ are given in Table A.I, and are based on data published by Mayoufi et al. (2011), Jager et al. (2013), Lin et al. (2014), and Clain (2014).

Carbon dioxide is a non-ideal gas, particularly near its critical point. The phenomenological formulae herein have been established from the numerical data published by IIF-IIR (2003) for density and by Span and Wagner (1996) for specific heat.

Two kinds of equation of state are used for density. When pressure is less than 5MPa, far below the critical point, the $\mathrm{CO}_{2}$ vapor density is computed with the van der Waals equation: 


$$
P+a \cdot \rho^{2}=\frac{\rho}{1-\rho \cdot b} \cdot r \cdot T
$$

The best adjustment of the data within the domain $[0.5-5 \mathrm{MPa}]$ and $\left[0-50^{\circ} \mathrm{C}\right]$ is obtained with $a=272.525 \mathrm{~Pa} \cdot \mathrm{m}^{6} \cdot \mathrm{kg}^{-2}$ and $b=1.88406 \times 10^{-3} \mathrm{~m}^{3} \cdot \mathrm{kg}^{-1}$. In this article, when the $\mathrm{CO}_{2}$ density is calculated above $5 \mathrm{MPa}$, the temperature is always $50^{\circ} \mathrm{C}$. With this prescribed temperature, the density data for $5 \leq P \leq 8 \mathrm{MPa}$ are correctly fitted with a quadratic function: $\rho=92.4-20.60 \cdot \pi+4.571 \cdot \pi^{2}$, in $\mathrm{kg} \cdot \mathrm{m}^{-3}$.

For the specific heat at constant volume $c_{v}$ of gaseous $\mathrm{CO}_{2}$, the data lying in the domain [0.1-7MPa $]$ and $\left[5-70^{\circ} \mathrm{C}\right]$ are correctly fitted with the following phenomenologícal function: $c_{v V}=C_{0}+C_{1} \cdot \pi+C_{4} \cdot \pi^{4}, \quad$ with $\quad C_{0}=541+0.98 \cdot \theta, \quad C_{1}=37.2 \cdot \exp (-0.01277 \cdot \theta)$, $C_{4}=0.715 \cdot \exp (-0.07 \cdot \theta)$, all in $\mathrm{J}_{\mathrm{kg}}{ }^{-1} \cdot \mathrm{K}^{-1}$.

\section{Appendix B: Justification of two simplifying assumptions}

B1: Heat input into the storage tanks through their thermal insulation

The insulating material considered herein consists of $30 \mathrm{~cm}$ of Ethylene-Propylene rubber foam, the thermal conductivity of which is $0.037 \mathrm{~W} \cdot \mathrm{m}^{-1} \cdot \mathrm{K}^{-1}$. A pessimistic temperature difference of $25 \mathrm{~K}$ between indoor air and tank interior is considered. Two cases are considered here-under.

Big storage tanks: Configuration A with $X^{m}=0.26$. Assuming that Tank $1\left(100 \mathrm{~m}^{3}\right)$ consists of three spherical tanks, $4 \mathrm{~m}$ in diameter, the conductive heat flux is $540 \mathrm{~W}$. With four cylinders, $4 \mathrm{~m}$ in diameter and height, Tank $2\left(200 \mathrm{~m}^{3}\right)$ receives $1.5 \mathrm{~kW}$. When integrated over 16 hours, the global heat input into the storage system is $0.12 \mathrm{GJ}$, i.e. $1.8 \%$ of the total stored heat.

Small storage tanks: Configuration B, slurry $C O$ with $X^{m}=0.32$. With two spherical tanks, $3.8 \mathrm{~m}$ in diameter, Tank $1\left(57 \mathrm{~m}^{3}\right)$ receives about $330 \mathrm{~W}$, and Tank $2\left(20 \mathrm{~m}^{3}\right.$, one cylinder, $3 \mathrm{~m}$ in diameter and height) receives $210 \mathrm{~W}$. Time integration gives a total heat input of $31 \mathrm{MJ}$, i.e. $0.45 \%$ of the total stored heat.

B2: Volume of the cold-distribution loop. 
The Figure 1 of the article of Compingt et al. (2009) presents the kitchen as an approximately square surface: its characteristic length is in the range $40-45 \mathrm{~m}$. Figure 5 of the same article displays three circuits, with respective diameters of 40, 50 and $125 \mathrm{~mm}$, plus some by-passes of diameter $30 \mathrm{~mm}$ around the slurry tank. When assuming $80 \mathrm{~m}$ as length of each circuit and $30 \mathrm{~m}$ for the total length of by-passes (both surely overestimated), the volume of slurry contained in the secondary loop is evaluated at $1.3 \mathrm{~m}^{3}$, i.e. $2 \%$ only of the storage tank. Neglecting this volume hardly modifies the results. 


\section{REFERENCES}

Bellas, I., Tassou, S.A., 2005. Present and future applications of ice slurries. International Journal of Refrigeration - Revue Internationale du Froid 28, 115-121.

Clain, P., 2014. Couplage entre le stockage et distribution de froid par coulis d'hydrates, Génie des Procédés et Technologies Avancées. Univ. Pierre et Marie Curie, Paris, p. 238.

Compingt, A., Blanc, P., Quidort, A., 2009. Slurry for refrigeration industrial kitchen application, in: Kauffeld, M. (Ed.), 8th IIR Conference on Phase Change Materials and Slurries for Refrigeration and Air Conditioning. Int. Inst. Refrigeration IIR-IIF, Karlsruhe, Germany, pp. 135-144.

Cowan, D., Gartshore, J., Chaer, I., Francis, C., Maidment, G., 2010. REAL Zero - Reducing refrigerant emissions \& leakage - feedback from the IOR Project Proc. Inst. R. 2009-10. IOR The Institute Of Refrigeration, p. 16.

Diamond, L.W., Akinfiev, N.N., 2003. Solubility of CO2 in water from -1.5 to 100 degrees C and from 0.1 to $100 \mathrm{MPa}$ : evaluation of literature data and thermodynamic modelling. Fluid Phase Equilibria 208, 265-290.

Fournaison, L., Delahaye, A., Chatti, I., Petitet, J.P., 2004. CO2 hydrates in refrigeration processes. Industrial \& Engineering Chemistry Research 43, 6521-6526.

Guilpart, J., Stamatiou, E., Fournaison, L., 2005. The control of ice slurry systems: an overview. International Journal of Refrigeration-Revue Internationale Du Froid 28, 98-107.

IIF-IIR, 2003. R744 CO2 dioxyde de carbone : Propriétés thermophysiques. IIF-IIR, Paris.

Ilani-Kashkouli, P., Mohammadi, A.H., Naidoo, P., Ramjugernath, D., 2016. Hydrate phase equilibria for $\mathrm{CO} 2, \mathrm{CH} 4$, or $\mathrm{N} 2+$ tetrabutylphosphonium bromide (TBPB) aqueous solution. Fluid Phase Equilibria 411, 88-92.

Jager, A., Vins, V., Gernert, J., Span, R., Hruby, J., 2013. Phase equilibria with hydrate formation in $\mathrm{H} 2 \mathrm{O}+\mathrm{CO} 2$ mixtures modeled with reference equations of state. Fluid Phase Equilibria 338, 100-113.

Jerbi, S., Delahaye, A., Fournaison, L., Haberschill, P., 2010. Characterization of CO2 hydrate formation and dissociation kinetics in a flow loop. International Journal of Refrigeration-Revue Internationale Du Froid 33, 1625-1631.

Kang, S.P., Lee, H., Ryu, B.J., 2001. Enthalpies of dissociation of clathrate hydrates of carbon dioxide, nitrogen, (earbon dioxide+ nitrogen), and (carbon dioxide + nitrogen+ tetrahydrofuran). The Journal of Chemical Thermodynamics 33, 513-521.

Lin, W., Dalmazzone, D., Fuerst, W., Delahaye, A., Fournaison, L., Clain, P., 2014. Thermodynamic properties of semiclathrate hydrates formed from the TBAB plus TBPB plus water and CO2 + TBAB + TBPB plus water systems. Fluid Phase Equilibria 372, 63 68.

Marinhas, S., Delahaye, A., Fournaison, L., 2007. Solid fraction modelling for CO2 and CO2THF hydrate slurries used as secondary refrigerants. International Journal of RefrigerationRevue Internationale Du Froid 30, 758-766.

Marinhas, S., Delahaye, A., Fournaison, L., Dalmazzone, D., Furst, W., Petitet, J.P., 2006. Modelling of the available latent heat of a $\mathrm{CO} 2$ hydrate slurry in an experimental loop applied to secondary refrigeration. Chemical Engineering and Processing 45, 184-192.

Mayoufi, N., Dalmazzone, D., Delahaye, A., Clain, P., Fournaison, L., Fuerst, W., 2011. Experimental Data on Phase Behavior of Simple Tetrabutylphosphonium Bromide (TBPB) 
and Mixed CO2 + TBPB Semiclathrate Hydrates. Journal of Chemical and Engineering Data 56, 2987-2993.

Mayoufi, N., Dalmazzone, D., Fürst, W., Delahaye, A., Fournaison, L., 2010. CO2 Enclathration in Hydrates of Peralkyl-(Ammonium/Phosphonium) Salts: Stability Conditions and Dissociation Enthalpies. Journal of Chemical \& Engineering Data 55, 1271-1275.

Mota-Babiloni, A., Navarro-Esbri, J., Barragan-Cervera, A., Moles, F., Peris, B., Verdu, G., 2015. Commercial refrigeration - An overview of current status. International Journal of Refrigeration-Revue Internationale Du Froid 57, 186-196.

Ogawa, T., Ito, T., Watanabe, K., Tahara, K.I., Hiraoka, R., Ochiai, J.I., Ohmura, R., Mori, Y.H., 2006. Development of a novel hydrate-based refrigeration system: A preliminary overview. Applied Thermal Engineering 26, 2157-2167.

Ogoshi, H., Takao, S., 2004. Air-conditioning system using clathrate hydrate slurry, JFE TECHNICAL REPORT. JFE, pp. 1-5.

Pons, M., Hoang, H.-M., Delahaye, A., Fournaison, L., 2015. Thermodynamic analysis of secondary refrigeration loops: effects of slurry type and flow conditions, in: Bédécarrats, J.-P. (Ed.), ECOS2015: 28th International Conference on Efficiency, Cost, Optimization, Simulation and Environmental Impact of Energy Systems. Pau Univ., Pau, France, p. 51633.pdf.

Serre, P., 2016. Personal Communication.

Shi, L.-L., Liang, D.-Q., Li, D.-L., 2013. Phase Equilibrium Data of Tetrabutylphosphonium Bromide Plus Carbon Dioxide or Nitrogen Semiclathrate Hydrates. Journal of Chemical \& Engineering Data 58, 2125-2130.

Sloan, E.D., Koh, C.A., 2008. Clathrate Hydrates of Natural Gases Third Edition Preface, 3rd ed. CRC Press-Taylor \& Francis Group, Boca Raton, FL.

Span, R., Wagner, W., 1996. A new equation of state for carbon dioxide covering the fluid region from the triple-point temperature to $1100 \mathrm{~K}$ at pressures up to $800 \mathrm{MPa}$. Journal of Physical and Chemical Reference Data 25, 1509-1596.

Wang, K., Eisele, M., Hwang, Y., Radermacher, R., 2010. Review of secondary loop refrigeration systems. International Journal of Refrigeration-Revue Internationale Du Froid $33,212-234$.

Yang, S.O., Yang, I.M., Kim, Y.S., Lee, C.S., 2000. Measurement and prediction of phase equilibria for water plus CO2 in hydrate forming conditions. Fluid Phase Equilibria 175, 75-89.

Yoon, J.-H., Yamamoto, Y., Komai, T., Haneda, H., Kawamura, T., 2003. Rigorous Approach to the Prediction of the Heat of Dissociation of Gas Hydrates. Industrial \& Engineering Chemistry Research 42, 1111-1114.

Youssef, Z., Delahaye, A., Huang, L., Trinquet, F., Fournaison, L., Pollerberg, C., Doetsch, C., 2013. State of the art on phase change material slurries. Energy Conversion and Management 65, 120-132.

Zhang, P., Ye, N., Zhu, H., Xiao, X., 2013. Hydrate Equilibrium Conditions of Tetra-nbutylphosphonium Bromide + Carbon Dioxide and the Crystal Morphologies. Journal of Chemical \& Engineering Data 58, 1781-1786.

Fig. 1: Process flow diagram of the secondary refrigeration system. 1: Tank 1; 2: Tank 2;

$3^{*}:$ control valve; $4^{*}: \mathrm{CO}_{2}$ compressor; $5^{*}$ : heat exchanger Air/ $\mathrm{CO}_{2} ; 6$ : slurry stirrer; 7 : control 
valve toward crystal generation; 8: slurry pump in the secondary loop; 9: user's heat exchanger; 10: cyclone; $V$ : Vapor; $S L$ : Slurry. ${ }^{*}$ The components 3, 4, and 5, are only present in Configuration B.

Fig. 2: Schematic representation of the daily pressure cycle. Solid lines: Configuration A; dashed lines: Configuration B.

Fig. 3: Volumes of Tank 1 (bottom) and of both tanks (top) in Configuration A. Solid lines for the two $C O$ cases CO_I $(\nabla)$ and $C O \_I I(\Delta)$; dashed lines for the MH cases MH_I (+) and MH_II (»).

Fig. 4: Volumes of Tank 1 (bottom and left Y-axis) and of both tanks (top and right Y-axis) in Configuration B. Same symbols as in Fig. 3.

Fig. 5: The four isentropic compression paths of $\mathrm{CO}_{2}$ in the $P$ - $h$ diagram (courtesy IIF-IIR), up to $8 \mathrm{MPa}$ for the $\mathrm{CO}$ cases, and up to $4 \mathrm{MPa}$ for the $\mathrm{MH}$ cases. The corresponding points at $50^{\circ} \mathrm{C}$ are also displayed $(\bullet)$.

Table 1 - Operating temperatures $\left[{ }^{\circ} \mathrm{C}\right]$ and pressures $[\mathrm{MPa}]$ for the cases under consideration.

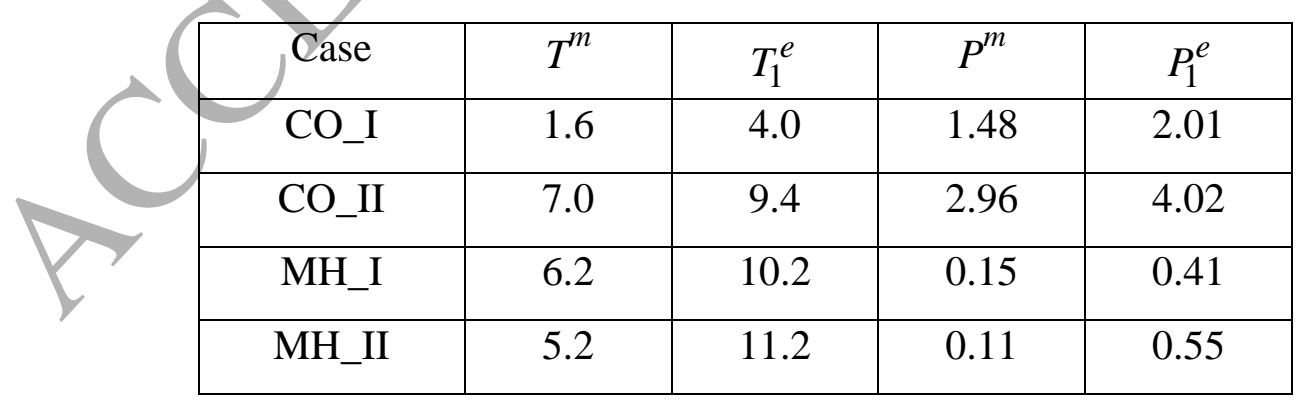


Table 2: Distribution of the amount of $\mathrm{CO}_{2}$ released by crystal melting $\left(-\Delta m_{C S}\right)$ toward the liquid phase $\left(\Delta m_{C L}\right)$ and toward Tank $2\left(\Delta m_{V 2}\right)$, calculated with $X^{m}=0.36$ and $X^{e}=0$. With $\left(-\Delta m_{S}\right)=$ mass of melted crystal [all masses in tons] and $\rho_{V 2}^{e}=$ vapor density in Tank 2 at $t^{e}$ $\left[\mathrm{kg} \cdot \mathrm{m}^{-3}\right]$.

\begin{tabular}{|c|c|c|c|c|}
\hline$\Delta m_{\bullet}=m_{\bullet}^{e}-m_{\bullet}^{m}$ & CO_I & CO_II & MH_I & MH_II \\
\hline$-\Delta m_{S}$ & 17.8 & 17.8 & 26.6 & 24.7 \\
\hline$-\Delta m_{C S}$ & 4.52 & 4.52 & 1.89 & 1.75 \\
\hline$\Delta m_{C L}$ & 0.93 & 1.16 & 0.32 & 0.49 \\
\hline$\Delta m_{V 2}$ & 3.42 & 3.08 & 1.54 & 1.23 \\
\hline$\rho_{V 2}^{e}$ & 44.6 & 83.2 & 7.4 & 10.0 \\
\hline
\end{tabular}

Table 3: Compression work $W_{\text {comp }}$ and heat quantity $Q_{H X 2}$ at the $\mathrm{Air} / \mathrm{CO}_{2}$ exchanger [GJ], calculated with $\eta_{i}=0.75$ and for $X^{m}=0.36$ and $X^{e}=0$. Corresponding power rates with 16-hour daytime periods $[\mathrm{kW}] . \Delta Q_{\left(20^{\circ} \mathrm{C}\right)}$ : Global impact when cooling the vapor down to $20^{\circ} \mathrm{C}$.

\begin{tabular}{|c|c|c|c|c|}
\hline & CO_I & CO_II & MH_I & MH_II \\
\hline$W_{\text {comp }}[\mathrm{GJ}]$ & 0.31 & 0.125 & 0.26 & 0.165 \\
\hline$Q_{H X 2}[\mathrm{GJ}]$ & -0.39 & -0.10 & -0.26 & -0.16 \\
\hline$\dot{W}_{\text {comp }}[\mathrm{kW}]$ & 5.4 & 2.2 & 4.6 & 2.9 \\
\hline$\dot{Q}_{H X 2}[\mathrm{~kW}]$ & 6.7 & 1.8 & 4.5 & 2.8 \\
\hline$\Delta Q_{\left(20^{\circ} \mathrm{C}\right)}[\mathrm{GJ}]$ & -0.65 & -0.73 & -0.05 & -0.04 \\
\hline
\end{tabular}

Table A.1: Material properties used in the calculations: stoichiometry of the crystals (water, additive, and $\mathrm{CO}_{2}$ ), densities and heat capacities of the crystals and solution, and enthalpy of fusion. $x$ is the TBPB mass fraction in the aqueous solution. 


\begin{tabular}{|c|c|c|}
\hline Slurry Code: & $C O$ & $M H$ \\
\hline$Y_{W}$ & 0.746 & 0.587 \\
\hline$Y_{A}$ & 0 & 0.342 \\
\hline$Y_{C}$ & 0.254 & 0.071 \\
\hline$\rho_{S}\left[\mathrm{~kg} \cdot \mathrm{m}^{-3}\right]$ & 1066 & 1233 \\
\hline$\rho_{L}\left[\mathrm{~kg} \cdot \mathrm{m}^{-3}\right]$ & 1000 & $1000+80 \cdot x$ \\
\hline$c_{p S}\left[\mathrm{~J} \cdot \mathrm{kg}^{-1} \cdot \mathrm{K}^{-1}\right]$ & 2085 & 2685 \\
\hline$c_{p L}\left[\mathrm{~J} \cdot \mathrm{kg}^{-1} \cdot \mathrm{K}^{-1}\right]$ & 4198 & $4180-1568 \cdot x$ \\
\hline$\Delta H\left[\mathrm{~kJ} \cdot \mathrm{kg}^{-1}\right]$ & 374 & 223.5 \\
\hline
\end{tabular}

